\title{
Synthesis and photoluminescence characterization of $\mathrm{Ce}^{3+}$ and $\mathrm{Dy}^{3+}$ activated $\mathrm{ALa}\left(\mathrm{WO}_{4}\right)_{2}(\mathrm{~A}=\mathrm{Na}$ and $\mathrm{Li})$ novel phosphors
}

\author{
PARAG NIMISHE and S J DHOBLE* \\ Department of Physics, RTM Nagpur University, Nagpur 440 033, India
}

MS received 1 October 2010

\begin{abstract}
In this paper, we report the synthesis of $\mathrm{Ce}^{3+}$ and $\mathrm{Dy}^{3+}$ activated alkali lanthanide tungstates, $\mathrm{ALa}\left(\mathrm{WO}_{4}\right)_{2}$ (where $\mathrm{A}=\mathrm{Na}$ and $\left.\mathrm{Li}\right)$, prepared by solid state reaction method. The prepared phosphors were characterized by X-ray diffraction and photoluminescence techniques. The $\mathrm{NaLa}\left(\mathrm{WO}_{4}\right)_{2}: \mathrm{Dy}^{3+}$ and $\mathrm{LiLa}\left(\mathrm{WO}_{4}\right)_{2}: \mathrm{Dy}^{3+}$ phosphors show two emission peaks at around 574 and $486 \mathrm{~nm}\left(\lambda_{\text {exc }}=354 \mathrm{~nm}\right)$. $\mathrm{NaLa}\left(\mathrm{WO}_{4}\right)_{2}: \mathrm{Ce}^{3+}$ and $\mathrm{LiLa}\left(\mathrm{WO}_{4}\right)_{2}: \mathrm{Ce}^{3+}$ show two emission peaks at around 378 and $425 \mathrm{~nm}\left(\lambda_{\text {exc }}=350 \mathrm{~nm}\right)$. Excitation wavelengths of $\mathrm{Ce}^{3+}$ and $\mathrm{Dy}^{3+}$ activated alkali lanthanide tungstates are in near $\mathrm{UV}$ region i.e. $\mathrm{Hg}$ free excitation. These characterizations of phosphors are applicable for solid state lighting. Accordingly, $\mathrm{Ce}^{3+}$ and $\mathrm{Dy}^{3+}$ activated $\mathrm{NaLa}_{(}\left(\mathrm{WO}_{4}\right)_{2}$ and LiLa $\left(\mathrm{WO}_{4}\right)_{2}$ may be the promising materials for solid state lighting applications.
\end{abstract}

Keywords. XRD; photoluminescence; NUV excitation; novel phosphor; solid state lighting.

\section{Introduction}

The light emitting diode (LED) has attracted great attention for use as an illuminator for solid-state lighting (Feldmann et al 2003; Schubert and Kim 2005). There are several approaches for a white light source using LEDs. Among them the phosphor-based white light source is the most promising. In this system, three red, green and blue phosphors absorb near-UV light from the UV-LED, generating white light. Even though many phosphors for white LEDs are currently available, blue, yellow, green and red phosphors still have problems associated with low brightness and chemical instability (Neeraj et al 2004; Schubert and Kim 2005). Therefore, demand for new blue, yellow, green and red phosphors applicable to white LEDs has increased. Most phosphors show a tendency toward strong energy absorption in the region of wavelengths $<300 \mathrm{~nm}$ due to the charge transfer and $4 f_{n-4} f_{n-1} 5 d$ transition of lanthanide ions (Blasse and Grabmaier 1994). However, the LED used in solid-state lighting provides near-UV light in the range 380-410 nm, which necessitates the new blue, yellow, green and red phosphors to be excited by these wavelengths in the range and to produce high brightness.

The tungstates show a distinctive polymorphic structure (Mokhosoev et al 1978; Tzunov et al 1986). There are several tungstates like $\mathrm{MgWO}_{4}, \mathrm{AlWO}_{4}$ and others which are monoclinic, whereas $\mathrm{CaWO}_{4}, \mathrm{SrWO}_{4}, \mathrm{BaWO}_{4}$ are tetragonal. The polymorphism is observed in alkai double tungstates too. Among the compounds being reported herein, $\mathrm{KLa}\left(\mathrm{WO}_{4}\right)_{2}$

*Author for correspondence (sjdhoble@ rediffmail.com) shows monoclinic structure. In $\mathrm{CaWO}_{4}\left(\right.$ Scheelite), the $\mathrm{Ca}^{2+}$ ion can be replaced alternately by a monovalent $\mathrm{A}^{+}$ion and a trivalent lanthanide ion, $\mathrm{Ln}^{3+}$ and can then be written as $\mathrm{ALn}\left(\mathrm{WO}_{4}\right)_{2}$.

Excellent mechanical (Dieke 1968), thermal and chemical (Shao et al 2009) stabilities of $\mathrm{ALn}\left(\mathrm{WO}_{4}\right)_{2}$ are of prime importance from the point of view of their technological and commercial applications. We have chosen $\mathrm{La}^{3+}$ cation to represent the lanthanide cations, $\mathrm{Ln}^{3+}$, in $\mathrm{ALn}\left(\mathrm{WO}_{4}\right)_{2}$ materials. In tungstate compounds, $\mathrm{W}^{6+}$ is coordinated by four oxygen atoms in a tetrahedral site, and the rare-earth/sodium (or lithium) ions occupy eight-coordinated sites.

The alkali rare earth tungstates have been studied so far mostly from the view point of their laser applications. Luminescence characterization of these materials has not been studied much for their lighting applications. Moreover, the luminescent properties of all the potential activators such as $\mathrm{Ce}^{3+}$ and $\mathrm{Dy}^{3+}$ activated ions have not been adequately studied. Only a few ions like $\mathrm{Nd}^{3+}, \mathrm{Sm}^{3+}, \mathrm{Tm}^{3+}, \mathrm{Yb}^{3+}$ (Güell et al 2007), $\mathrm{Ho}^{3+}$ (Kasprowicz et al 2007), $\mathrm{Er}^{3+}$ (Mateos et al 2002) etc are reported as good activators in tungstate hosts for laser applications. This is probably because of the fact that $\mathrm{Ce}^{3+}$ and $\mathrm{Dy}^{3+}$ ions doped systems are not promising laser materials as other rare earth based systems. However, they can be excellent phosphor materials. Recently, Gu et al (2010) reported results of the morphological and luminescent studies of $\mathrm{NaLa}\left(\mathrm{WO}_{4}\right)_{2}: \mathrm{Eu}$ synthesized by hydrothermal process. Tang and Wang (2004) synthesized the $\mathrm{KLa}\left(\mathrm{WO}_{4}\right)_{2}$ : $\mathrm{Yb}^{3+}$ crystals and Huang et al (2004) synthesized $\mathrm{LiLa}\left(\mathrm{WO}_{4}\right)_{2}: \mathrm{Nd}^{3+}$ crystals by $\mathrm{CZ}$ method and investigated the absorbance and emission spectra for laser applications. The family of alkali lanthanide tungstate compounds, 
generally represented by the formula, $\mathrm{ALn}\left(\mathrm{WO}_{4}\right)_{2}$, where A and Ln are alkali and lanthanide cations, respectively has shown many interesting properties which find their applications in laser host materials (Kaminskii et al 1996; Liu et al 2005; Garcia-Cortes et al 2007), phosphors of LED, X-ray detectors (Kaminskii et al 1999; Neeraj et al 2004) etc. They are also used as a cooling agent in adiabatic demagnetization for obtaining very low temperatures (Kovács et al 2005). Therefore, now a days $\mathrm{Ce}^{3+}$ and $\mathrm{Dy}^{3+}$ activated novel alkali lanthanide tungstates have become interesting materials in the field of lighting.

As mercury lamps are posing alarming environmental problems, it is the need of the hour to develop technology to produce mercury-free lamps. Under this condition, what is the new lighting system of the near future? White
LEDs and organic ELs are possible candidates. However, both technologies are faced with knotty problems for lighting applications. Recently, luminescence materials doped with $\mathrm{Dy}^{3+}$ have drawn much interest for their white emission (Dominiak-Dzik et al 2004; Xiu et al 2006; Liang et al 2008). In general, $\mathrm{Dy}^{3+}$ has two dominant bands in the emission spectra in many host matrices. The band located at $571 \mathrm{~nm}$ (yellow) corresponds to the hypersensitive transition ${ }^{4} F_{9 / 2} \rightarrow{ }^{6} H_{13 / 2}(\mathrm{DL}=2, \mathrm{DJ}=2)$, and another band located at $478 \mathrm{~nm}$ (blue) is due to the transition ${ }^{4} F_{9 / 2} \rightarrow{ }^{6} H_{15 / 2}$. By adjusting the yellow-to-blue intensity ratio (Y/B) value appropriately, it is possible to obtain near-white emission with only $\mathrm{Dy}^{3+}$-activated luminescence materials. Therefore, the $\mathrm{Dy}^{3+}$-activated phosphors are promising white light phosphors and can be used in mercury-free lamps. For

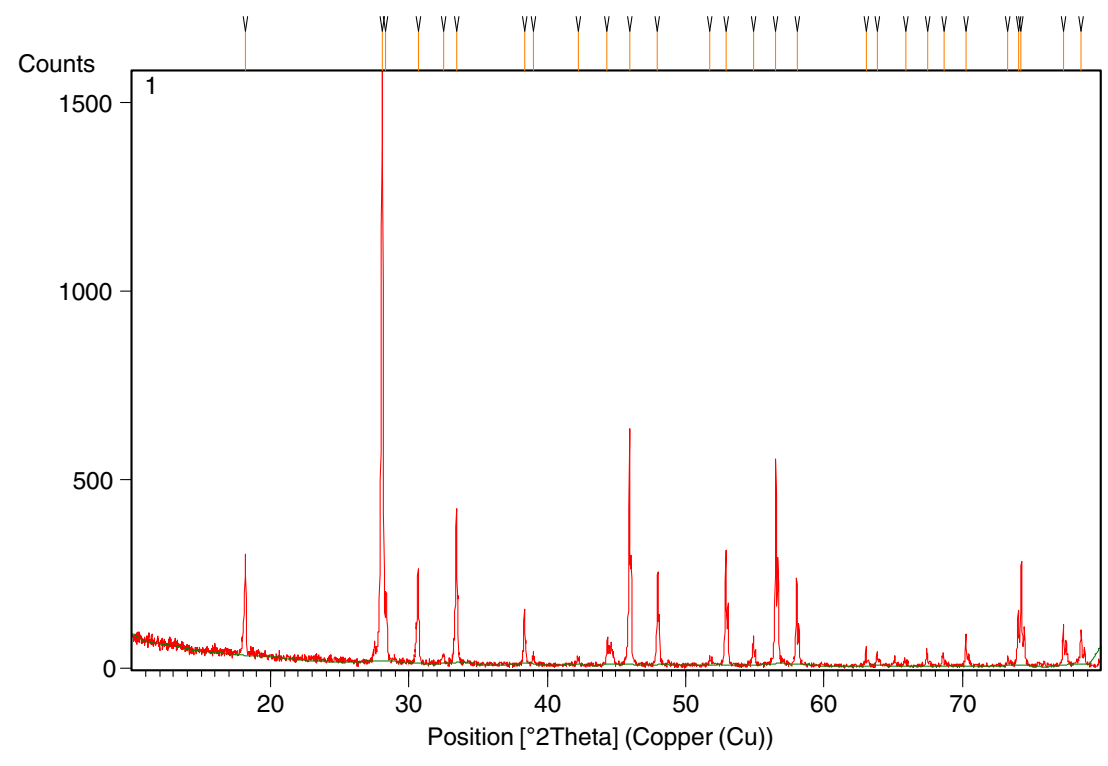

Figure 1. X-ray diffraction pattern of $\mathrm{NaLa}\left(\mathrm{WO}_{4}\right)_{2}$.

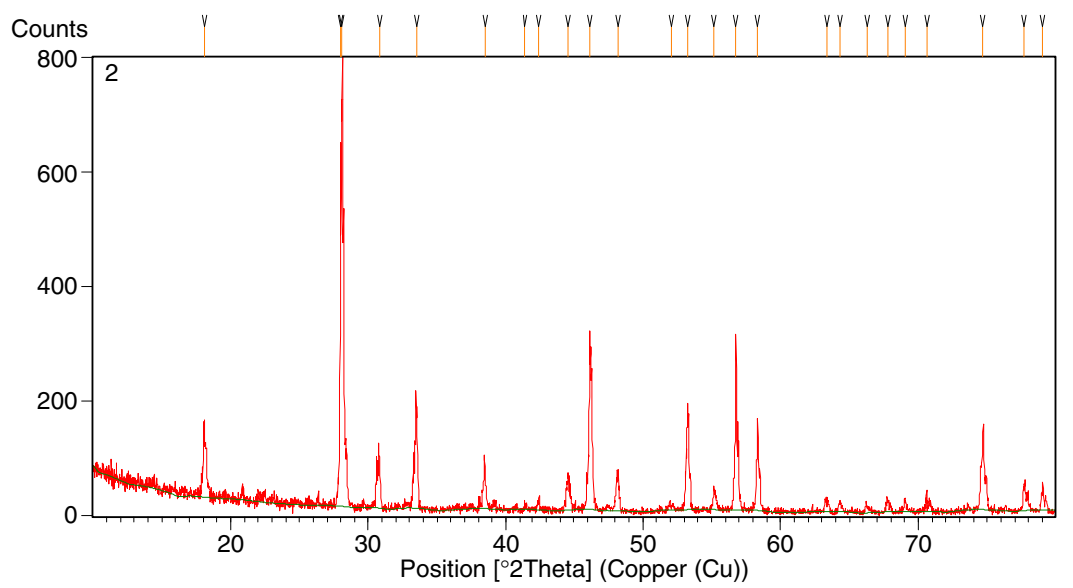

Figure 2. X-ray diffraction pattern of $\mathrm{LiLa}\left(\mathrm{WO}_{4}\right)_{2}$. 
mercury-free lamps, the excitation energy mainly composed of VUV radiation but VUV energy is mostly absorbed by the host crystal, if the energy can be transferred from host to rare-earth (RE) ions then the rare earth ions can emit visible light. So the host absorption intensity is very important for VUV-excited phosphors applied in mercury-free lamp.

Accordingly, mercury-free lamp novel luminescent materials with improved properties are in high demand. In this paper, we report on the preparation and photoluminescence characterization of novel $\mathrm{Ce}^{3+}$ and $\mathrm{Dy}^{3+}$ activated alkali lanthanide tungstates, $\mathrm{ALa}\left(\mathrm{WO}_{4}\right)_{2}$ (where $\mathrm{A}=\mathrm{Na}$ and $\mathrm{Li}$ ) phosphors prepared by the solid state diffusion method. To the best of our knowledge, this is for the first time that $\mathrm{Ce}^{3+}$ and $\mathrm{Dy}^{3+}$ activated $\mathrm{ALa}\left(\mathrm{WO}_{4}\right)_{2}$ (where $\mathrm{A}=\mathrm{Na}$ and $\mathrm{Li}$ ) phosphors, synthesized through this approach towards their application in the solid state lighting, are reported.

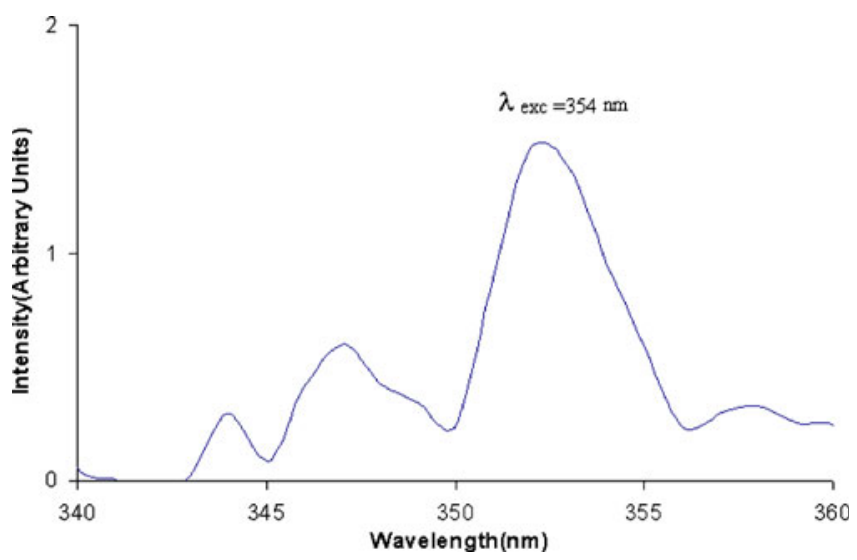

Figure 3. Excitation spectra of $\mathrm{NaLa}\left(\mathrm{WO}_{4}\right)_{2}: \mathrm{Dy}^{3+}$ and $\mathrm{LiLa}\left(\mathrm{WO}_{4}\right)_{2}: \mathrm{Dy}^{3+}$, monitored at $574 \mathrm{~nm}$.

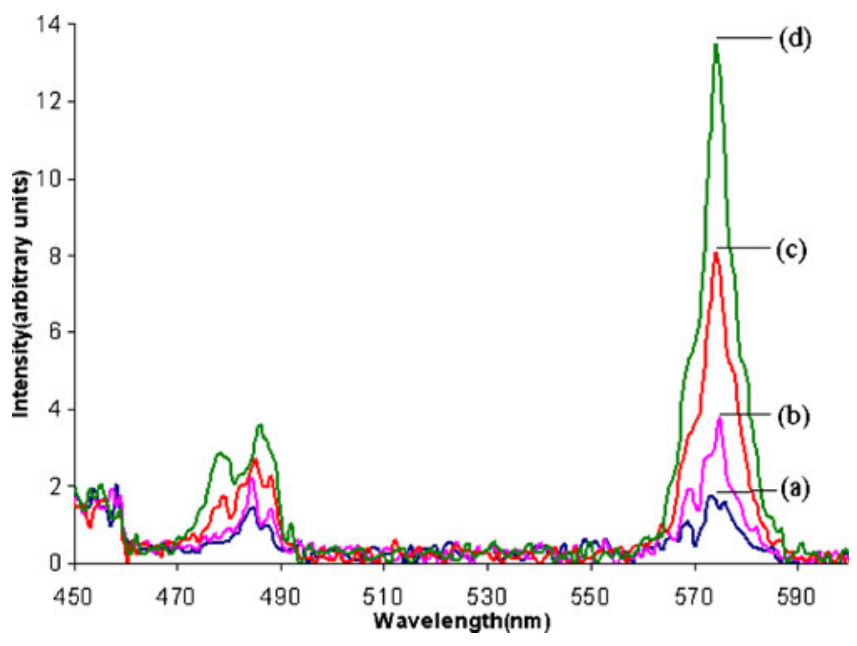

Figure 4. Emission spectra of $\mathrm{NaLa}\left(\mathrm{WO}_{4}\right)_{2}: \mathrm{Dy}^{3+}$ at $\lambda_{\mathrm{exc}}=$ $356 \mathrm{~nm}$, corresponding to $\mathrm{Dy}^{3+}$ concentrations: (a) $0.1 \mathrm{~m} \%$, (b) $0.2 \mathrm{~m} \%$, (c) $0.5 \mathrm{~m} \%$ and (d) $1 \mathrm{~m} \%$.

\section{Experimental}

All the three phosphors, viz. $\mathrm{NaLa}\left(\mathrm{WO}_{4}\right)_{2}: \mathrm{Dy}^{3+}$ and $\mathrm{LiLa}\left(\mathrm{WO}_{4}\right)_{2}: \mathrm{Dy}^{3+}$ were prepared by the well known solid state reaction method. The starting chemicals, $\mathrm{ANO}_{3}$ (where $\mathrm{A}=\mathrm{Na}$ or $\mathrm{Li}$ ), $\mathrm{La}_{2} \mathrm{O}_{3}, \mathrm{Dy}_{2} \mathrm{O}_{3} / \mathrm{Ce}_{2} \mathrm{O}_{3}$ and $\mathrm{WO}_{3}$ with high purity of $99.9 \%$ were used. They were taken in stoichiometric amounts. The $\mathrm{Dy}^{3+}$ concentrations were varied from $0 \cdot 1$ to $1 \mathrm{~mol} \%$. The starting materials were mixed thoroughly for $1 \mathrm{~h}$ using the agate mortar pestle. The crushed samples were placed in a silica crucible and heated at $300^{\circ} \mathrm{C}$ in muffle furnace for $3 \mathrm{~h}$. Then, they were removed, crushed in the mortar pestle again and heated at $800^{\circ} \mathrm{C}$ for $24 \mathrm{~h}$. They were mixed intermittently. The stoichiometric reaction of the synthesized compounds is shown below. Finally, the samples in the furnace were allowed to cool down to room temperature.

$$
4 \mathrm{ANO}_{3}+2 \mathrm{La}_{2} \mathrm{O}_{3}+8 \mathrm{WO}_{3} \rightarrow 4 \mathrm{ALa}\left(\mathrm{WO}_{4}\right)_{2}+2 \mathrm{NO}_{2}+\mathrm{O}_{2},
$$

where $\mathrm{A}=\mathrm{Na}$ or $\mathrm{Li}$.

Several complementary methods were used to characterize the prepared phosphor. The prepared host lattice was characterized for their phase purity and crystallinity by X-ray powder diffraction (XRD) using PAN-analytical diffractometer $(\mathrm{Cu}-\mathrm{K} \alpha$ radiation $)$ at a scanning step of $0.01^{\circ}$, continue time $20 \mathrm{~s}$, in the range of $2 \theta$ from $10^{\circ}$ to $120^{\circ}$; the average crystallite size was calculated from the broadening of the Xray line (311) using Scherrer's equation. The surface morphology and particle size of the rare earth doped tungstate phosphors prepared in the present investigation were studied using scanning electron microscope. The photoluminescence measurement of excitation and emission were recorded on a Shimadzu RF5301PC Spectrofluorophotometer. The same amount of sample, $2 \mathrm{~g}$, was used for each measurement. Emission and excitation spectra were recorded using a spectral slit width of $1.5 \mathrm{~nm}$.

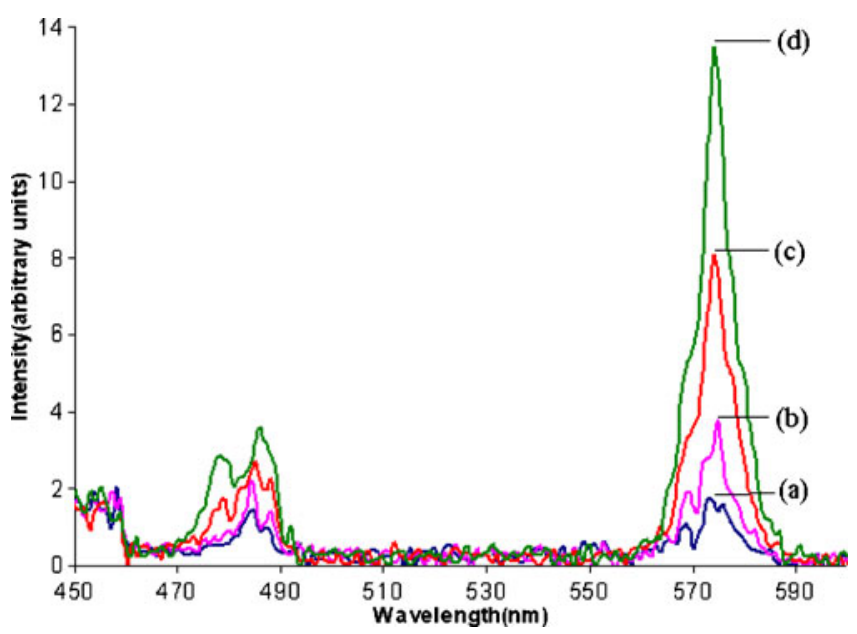

Figure 5. Emission spectra of $\mathrm{LiLa}\left(\mathrm{WO}_{4}\right)_{2}: \mathrm{Dy}^{3+}$ at $\lambda_{\text {exc }}=$ $354 \mathrm{~nm}$, corresponding to $\mathrm{Dy}^{3+}$ concentrations: (a) $0.1 \mathrm{~m} \%$, (b) $0.2 \mathrm{~m} \%$, (c) $0.5 \mathrm{~m} \%$ and (d) $1 \mathrm{~m} \%$. 


\section{Results and discussion}

\subsection{X-ray diffraction pattern}

Figures 1 and 2 show the X-ray diffraction (XRD) pattern of $\mathrm{NaLa}\left(\mathrm{WO}_{4}\right)_{2}$ and $\mathrm{LiLa}\left(\mathrm{WO}_{4}\right)_{2}$. Both the XRD patterns match well with the standard JCPDS file nos 79-1118 and 250829, respectively. The XRD patterns of these compounds do not indicate the presence or traces of reactants which is an indirect evidence of formation of desired compounds. The patterns also indicate that the final products i.e. $\mathrm{NaLa}\left(\mathrm{WO}_{4}\right)_{2}$ and $\mathrm{LiLa}\left(\mathrm{WO}_{4}\right)_{2}$, are formed in homogeneous form. Their calculated lattice parameters are in accordance with those of the JCPDS cards.

It is worth noting that no change is seen in the structures of the above compounds after doping of $\mathrm{Dy}^{3+}$ or $\mathrm{Ce}^{3+}$ ions.

\subsection{Photoluminescence characterization}

The excitation spectra of $\mathrm{NaLa}\left(\mathrm{WO}_{4}\right)_{2}: \mathrm{Dy}^{3+}$ and $\mathrm{LiLa}\left(\mathrm{WO}_{4}\right)_{2}: \mathrm{Dy}^{3+}$ phosphors are observed at $354 \mathrm{~nm}$ in both the phosphors (monitored at $574 \mathrm{~nm}$ ). Therefore, only the excitation spectrum of $\mathrm{LiLa}\left(\mathrm{WO}_{4}\right)_{2}: \mathrm{Dy}^{3+}$ is shown here in figure 3. The emission spectra of $\mathrm{NaLa}\left(\mathrm{WO}_{4}\right)_{2}: \mathrm{Dy}^{3+}$ and $\mathrm{LiLa}\left(\mathrm{WO}_{4}\right)_{2}: \mathrm{Dy}^{3+}$ compounds, observed in the range of 400-650 nm while keeping excitation wavelength at 354, are shown in figures 4 and 5 .

The PL emission is observed at 486 and $574 \mathrm{~nm}$ to have strikingly similar nature in both the phosphors, differing only in their relative PL peak intensity values. The PL emission peaks are observed at $574 \mathrm{~nm}$ in the yellow and 486 and $426 \mathrm{~nm}$ in the blue regions of visible spectrum, respectively. The peak at $574 \mathrm{~nm}$ is due to ${ }^{4} F_{9 / 2} \rightarrow{ }^{6} H_{13 / 2}$ transition of electric dipole moment whereas that at $486 \mathrm{~nm}$ is due to ${ }^{4} F_{9 / 2} \rightarrow{ }^{6} H_{15 / 2}$ transition of magnetic dipole due to Dy ${ }^{3+}$ ion. The $426 \mathrm{~nm}$ peak is observed due to the splitting of magnetic dipole moment. The peak intensities at wavelengths 574 and $486 \mathrm{~nm}$ are seen to be in increasing order with increasing concentration of $\mathrm{Dy}^{3+}$ ions and maximum intensity is observed in both phosphors at $1 \mathrm{~mol} \%$ of ions. The PL intensity of $\mathrm{LiLa}\left(\mathrm{WO}_{4}\right)_{2}: \mathrm{Dy}^{3+}$ phosphor is higher than that of $\mathrm{NaLa}\left(\mathrm{WO}_{4}\right)_{2}: \mathrm{Dy}^{3+}$ phosphor.

The PL emission increases with the concentration of activator ion, $\mathrm{Dy}^{3+}(1 \mathrm{~mol} \%)$. In the present case, the $\mathrm{Dy}^{3+}$ ion may enter into the host lattice to substitute $\mathrm{La}^{2+}$ or $\mathrm{Na}^{+} / \mathrm{Li}^{+}$or it may be located on surfaces of the crystals. The ionic radii of $\mathrm{Dy}^{3+}(91.2 \mathrm{pm})$ is much larger than $\mathrm{Li}^{+}(76 \mathrm{pm})$ and smaller than $\mathrm{La}^{2+}(103.2 \mathrm{pm})$ and $\mathrm{Na}^{+}$ $(102 \mathrm{pm})$. The first possibility is more feasible. Most of the $\mathrm{Dy}^{3+}$ ions are entering into the lattice $\mathrm{LiLa}\left(\mathrm{WO}_{4}\right)_{2}$ as compared to $\mathrm{NaLa}\left(\mathrm{WO}_{4}\right)_{2}$ phosphor and few of them are located at the surface. Its substitution at $\mathrm{Li}^{+}$site in $\mathrm{NaLa}\left(\mathrm{WO}_{4}\right)_{2}$ will lead to more distortion in the host in comparison to its substitution in $\mathrm{NaLa}\left(\mathrm{WO}_{4}\right)_{2}$ phosphor. Monovalent cations are charge compensates to divalent and trivalent ions, developed the symmetry in host lattice. The charge compensating defects in the immediate vicinity is likely to influence the local site symmetry of activator in the host lattics. This is reflected in the emission spectra, wherein asymmetry factor is higher in $\mathrm{LiLa}\left(\mathrm{WO}_{4}\right)_{2}$ sample compared to $\mathrm{NaLa}\left(\mathrm{WO}_{4}\right)_{2}$ phosphor. As $\mathrm{Dy}^{3+}$ ions progressively replace the $\mathrm{Li}^{+}$ions, an increase in PL emission intensity is observed and asymmetry factor progressively reduced. The low-symmetry location of $\mathrm{Dy}^{3+}$ results in predominant emission of ${ }^{4} F_{9 / 2} \rightarrow{ }^{6} H_{15 / 2}$ transition. Hence, $\mathrm{LiLa}\left(\mathrm{WO}_{4}\right)_{2}$ phosphors show strong PL emission intensity as compared to $\mathrm{NaLa}\left(\mathrm{WO}_{4}\right)_{2}$ phosphor when Dy is doped as shown in figure 5. Usually, a low doping gives weak luminescence, but excess doping perhaps causes quenching of luminescence. The maximum intensity of $\mathrm{Dy}^{3+}$ is observed at $1 \mathrm{~mol} \%$ as shown in table 1 .

Table 1. PL intensity comparison table.

\begin{tabular}{lcc}
\hline Compound & Wavelength (nm) & PL intensity (arb. units) \\
\hline $\mathrm{NaLa}\left(\mathrm{WO}_{4}\right)_{2}: \mathrm{Dy}_{0} \cdot 1$ & $573 \cdot 9699,485 \cdot 07$ & $8 \cdot 0492,0 \cdot 4422$ \\
$\mathrm{NaLa}\left(\mathrm{WO}_{4}\right)_{2}: \mathrm{Dy}_{0} \cdot 2$ & $573 \cdot 9699,485 \cdot 07$ & $4 \cdot 9599,2 \cdot 0796$ \\
$\mathrm{NaLa}\left(\mathrm{WO}_{4}\right)_{2}: \mathrm{Dy}_{0} \cdot 5$ & $573 \cdot 9699,485 \cdot 07$ & $2 \cdot 3549,2 \cdot 392$ \\
$\mathrm{NaLa}\left(\mathrm{WO}_{4}\right)_{2}: \mathrm{Dy}_{1}$ & $573 \cdot 9699,485 \cdot 07$ & $0 \cdot 2796,2 \cdot 9586$ \\
$\mathrm{LiLa}\left(\mathrm{WO}_{4}\right)_{2}: \mathrm{Dy}_{0} \cdot 1$ & $573 \cdot 9699,485 \cdot 07$ & $13 \cdot 3872,1 \cdot 255$ \\
$\mathrm{LiLa}\left(\mathrm{WO}_{4}\right)_{2}: \mathrm{Dy}_{0} \cdot 2$ & $573 \cdot 9699,485 \cdot 07$ & $08 \cdot 0286,1 \cdot 37$ \\
$\mathrm{LiLa}\left(\mathrm{WO}_{4}\right)_{2}: \mathrm{Dy}_{0} \cdot 5$ & $573 \cdot 9699,485 \cdot 07$ & $03 \cdot 8095,2 \cdot 7208$ \\
$\mathrm{LiLa}\left(\mathrm{WO}_{4}\right)_{2}: \mathrm{Dy}_{1}$ & $573 \cdot 9699,485 \cdot 07$ & $01 \cdot 6591,3 \cdot 5788$ \\
$\mathrm{Nala}\left(\mathrm{WO}_{4}\right)_{2}: \mathrm{Ce}_{1}$ & $379 \cdot 0700,425$ & $39 \cdot 3708,5 \cdot 2552$ \\
$\mathrm{NaLa}\left(\mathrm{WO}_{4}\right)_{2}: \mathrm{Ce}_{2}$ & $378 \cdot 0700,425$ & $25 \cdot 1024,4 \cdot 2118$ \\
$\mathrm{NaLa}\left(\mathrm{WO}_{4}\right)_{2}: \mathrm{Ce}_{5}$ & $378 \cdot 0700,425$ & $28 \cdot 5447,3 \cdot 07$ \\
$\mathrm{NaLa}\left(\mathrm{WO}_{4}\right)_{2}: \mathrm{Ce}_{10}$ & $378 \cdot 0700,426$ & $35 \cdot 8330,4 \cdot 7918$ \\
$\mathrm{LiLa}\left(\mathrm{WO}_{4}\right)_{2}: \mathrm{Ce}_{1}$ & $378,423 \cdot 9299$ & $34 \cdot 4780,5 \cdot 5437$ \\
$\mathrm{LiLa}\left(\mathrm{WO}_{4}\right)_{2}: \mathrm{Ce}_{2}$ & $379,425 \cdot 0000$ & $32 \cdot 0117,5 \cdot 1754$ \\
$\mathrm{LiLa}\left(\mathrm{WO}_{4}\right)_{2}: \mathrm{Ce}_{5}$ & $378,423 \cdot 9299$ & $21 \cdot 4725,3 \cdot 9379$ \\
$\mathrm{LiLa}\left(\mathrm{WO}_{4}\right)_{2}: \mathrm{Ce}_{10}$ & $378,423 \cdot 9299$ & \\
\hline
\end{tabular}


The PL emission intensity comparison is shown in table 1 which gives the values of concentrations and corresponding peak intensities for all the three $\mathrm{Dy}^{3+}$ activated phosphors. For a better comparison, figures 6 and 7 are given which correspond to the peaks at 576 and $486 \mathrm{~nm}$, respectively. It can be seen that amongst the three $\mathrm{Dy}^{3+}$ activated alkali double tungstate reported here, $\mathrm{LiLa}\left(\mathrm{WO}_{4}\right)_{2}: \mathrm{Dy}^{3+}$ shows the maximum intensities for all emission peaks.

Figure 8 shows schematic energy level diagram of $\mathrm{Dy}^{3+}$ ion. In general, $\mathrm{Dy}^{3+}$ has two dominant bands in the emission spectra in many host matrices. The blue emission band located at $486 \mathrm{~nm}$ due to ${ }^{4} F_{9 / 2} \rightarrow{ }^{6} H_{15 / 2}$ transition and the band located at $576 \mathrm{~nm}$ (yellow) corresponds to the hypersensitive ${ }^{4} F_{9 / 2} \rightarrow{ }^{6} H_{13 / 2}$ transition. By adjusting the yellowto-blue intensity ratio (Y/B) value appropriately, it is possible to obtain near white emission with only $\mathrm{Dy}^{3+}$-activated luminescence materials. Therefore, the $\mathrm{Dy}^{3+}$-activated phosphors are promising white light phosphors and can be used in mercury-free lamps.

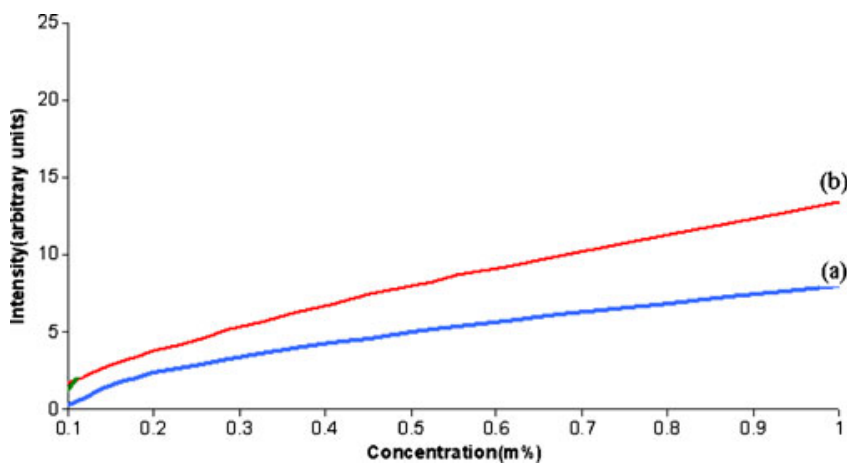

Figure 6. PL intensity of $574 \mathrm{~nm}$ peak corresponding to $\mathrm{Dy}^{3+}$ concentrations for phosphors (a) $\mathrm{NaLa}\left(\mathrm{WO}_{4}\right)_{2}: \mathrm{Dy}^{3+}$ and (b) $\mathrm{LiLa}\left(\mathrm{WO}_{4}\right)_{2}: \mathrm{Dy}^{3+}$.

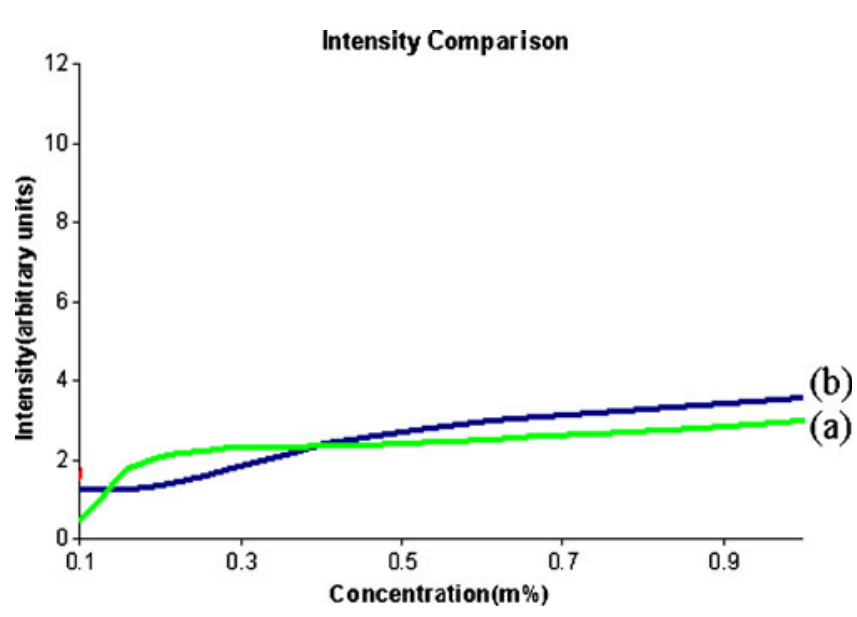

Figure 7. PL intensity of $485 \mathrm{~nm}$ peak corresponding to $\mathrm{Dy}^{3+}$ concentrations for phosphors (a) $\mathrm{NaLa}\left(\mathrm{WO}_{4}\right)_{2}: \mathrm{Dy}^{3+}$ and (b) $\mathrm{LiLa}\left(\mathrm{WO}_{4}\right)_{2}: \mathrm{Dy}^{3+}$.
$\mathrm{Ce}^{3+}$ is a very good candidate for studying the behaviour of $5 d$ electrons. $\mathrm{Ce}^{3+}$ has only one outer electron and only two spin-orbital splitting $4 f$ states $\left({ }^{2} F_{5 / 2}, 7 / 2\right)$. Thus, its excited state energy structure is simpler than that of the other trivalent rare-earth ions. The excitation spectra of the $\mathrm{NaLa}\left(\mathrm{WO}_{4}\right)_{2}: \mathrm{Ce}^{3+}$ and $\mathrm{LiLa}\left(\mathrm{WO}_{4}\right)_{2}: \mathrm{Ce}^{3+}$ are shown in figure 9, The excitation peak are observed in both the phosphors at $350 \mathrm{~nm}$. The emission spectra of these phosphors, taken while keeping excitation wavelength at $350 \mathrm{~nm}$, are shown in figures 10 and 11 , respectively. In both the phosphors of $\mathrm{NaLa}\left(\mathrm{WO}_{4}\right)_{2}: \mathrm{Ce}^{3+}$ and $\mathrm{LiLa}\left(\mathrm{WO}_{4}\right)_{2}: \mathrm{Ce}^{3+}$, the peaks are

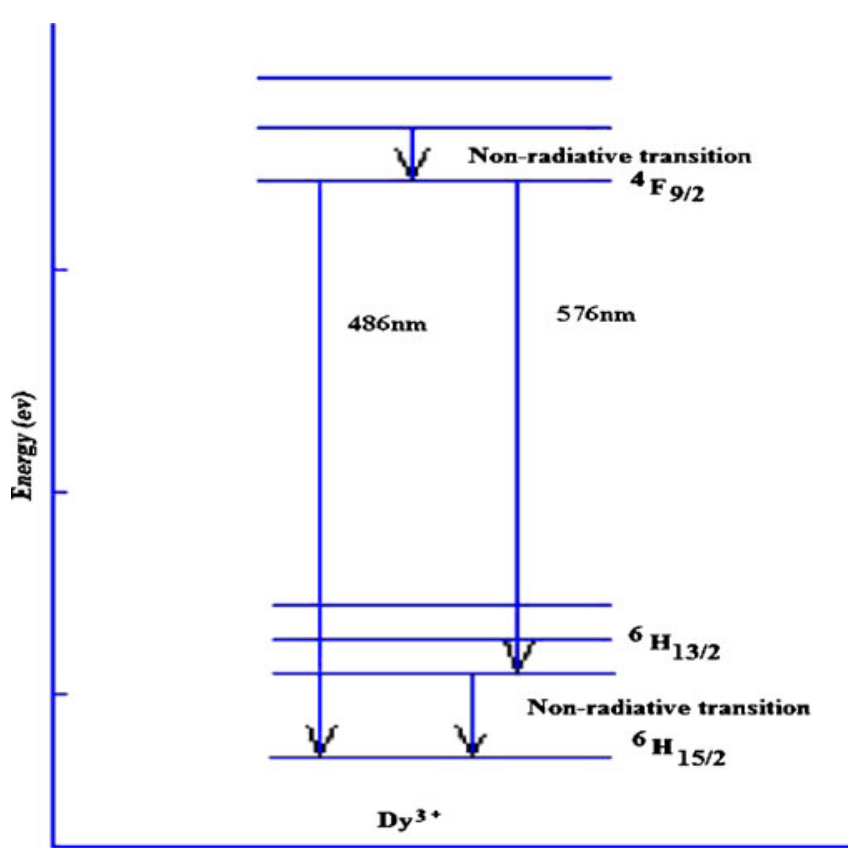

Figure 8. Schematic energy level diagram of $\mathrm{Dy}^{3+}$ ion.

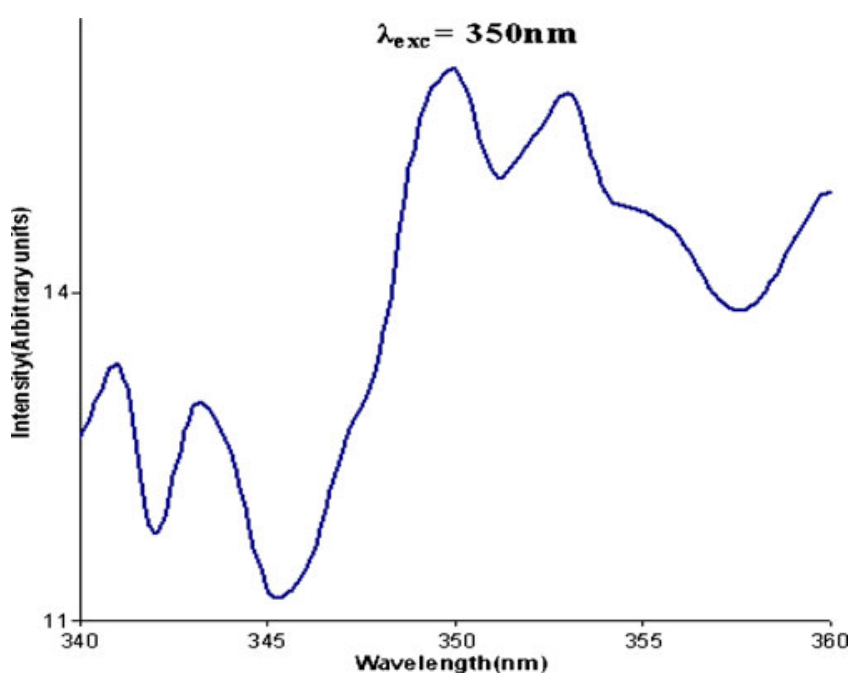

Figure 9. Excitation spectra of $\mathrm{LiLa}\left(\mathrm{WO}_{4}\right)_{2}: \mathrm{Ce}^{3+}$ monitored at $\mathrm{nm}$. 
observed around 378 and 425 indicating UV and blue emissions, respectively. A shoulder around $393 \mathrm{~nm}$ is also seen. The UV emission around $380 \mathrm{~nm}$ is most intense. The maximum intensity of $\mathrm{Ce}^{3+}$ ion are observed at 1 and $2 \mathrm{~mol} \%$ of $\mathrm{Ce}^{3+}$ ion among all the concentrations range from 01 to $10 \mathrm{~mol} \%$ in $\mathrm{NaLa}\left(\mathrm{WO}_{4}\right)_{2}: \mathrm{Ce}^{3+}$ and $\mathrm{LiLa}\left(\mathrm{WO}_{4}\right)_{2}: \mathrm{Ce}^{3+}$ phosphors, respectively.

It is interesting to note, from figures 10 and 11 also, that the emission in both $\mathrm{NaLa}\left(\mathrm{WO}_{4}\right)_{2}: \mathrm{Ce}^{3+}$ and

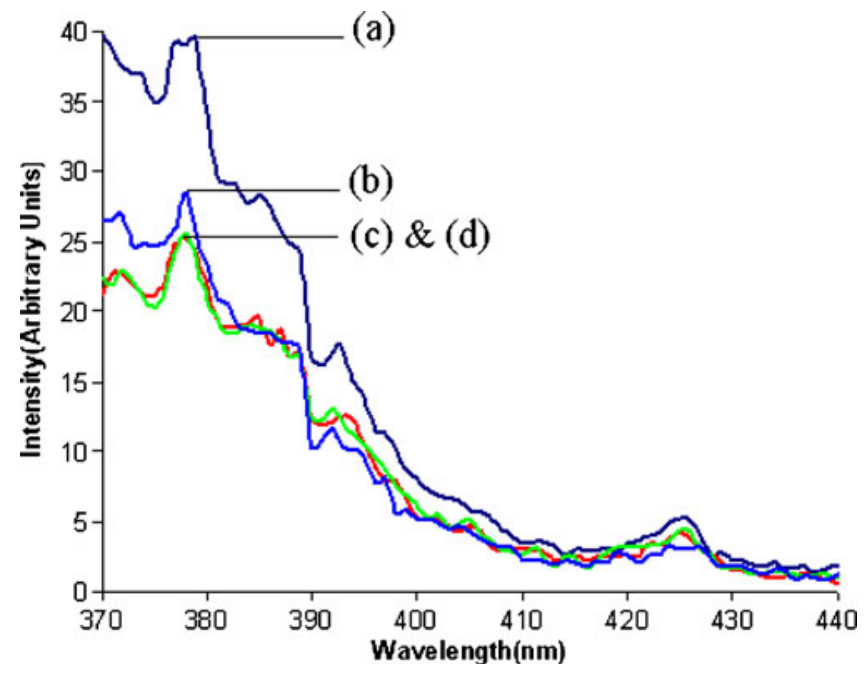

Figure 10. Emission spectra of $\mathrm{NaLa}\left(\mathrm{WO}_{4}\right)_{2}: \mathrm{Ce}^{3+}$. Peaks at $378 \mathrm{~nm}$ correspond to concentrations of $\mathrm{Ce}^{3+}$ ions at (a) $1 \mathrm{~m} \%$, (b) $2 \mathrm{~m} \%$, (c) $5 \mathrm{~m} \%$ and (d) $10 \mathrm{~m} \%$. Peaks at $25 \mathrm{~nm}$ for all concentrations almost overlap each other.

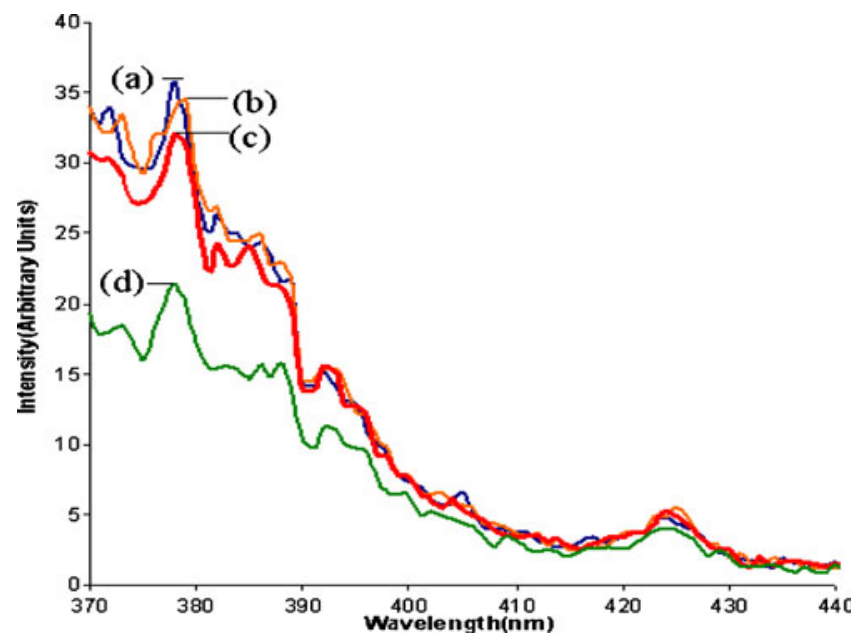

Figure 11. Emission spectra of $\mathrm{LiLa}\left(\mathrm{WO}_{4}\right)_{2}: \mathrm{Ce}^{3+}$. Peaks at $378 \mathrm{~nm}$ correspond to concentrations of $\mathrm{Ce}^{3+}$ ions at (a) $1 \mathrm{~m} \%$, (b) $2 \mathrm{~m} \%$, (c) $5 \mathrm{~m} \%$ and (d) $10 \mathrm{~m} \%$. Peaks at $425 \mathrm{~nm}$ for all concentrations almost overlap each other.
$\mathrm{LiLa}\left(\mathrm{WO}_{4}\right)_{2}: \mathrm{Ce}^{3+}$ has strikingly similar nature and differs only in their relative PL peak intensity values. From table 1, and figures 10 and 11, it is observed that the intensity of $\mathrm{LiLa}\left(\mathrm{WO}_{4}\right)_{2}: \mathrm{Ce}^{3+}$ is around similar intensity than that of $\mathrm{NaLa}\left(\mathrm{WO}_{4}\right)_{2}: \mathrm{Ce}^{3+}$ for all corresponding peaks.

\section{Conclusions}

The solid state diffusion method for synthesis of alkali rare earth double tungstates phosphors was found to be a suitable method for solid state lighting materials. It produced the desired phosphors in the homogeneous form; free from the traces of constituent reactants, which is confirmed from their XRD and photoluminescence characterization.

- The XRD characteristic shows the XRD data of prepared phosphors well match with standard XRD data.

- The photoluminescence studies of prepared phosphors, $\mathrm{NaLa}\left(\mathrm{WO}_{4}\right)_{2}: \mathrm{Dy}^{3+}$ and LiLa $\left(\mathrm{WO}_{4}\right)_{2}: \mathrm{Dy}^{3+}$, show the two emission peaks at around 574 and $486 \mathrm{~nm}\left(\lambda_{\mathrm{exc}}=356 \mathrm{~nm}\right)$.

- $\mathrm{NaLa}\left(\mathrm{WO}_{4}\right)_{2}: \mathrm{Ce}^{3+}$ and $\mathrm{LiLa}\left(\mathrm{WO}_{4}\right)_{2}: \mathrm{Ce}^{3+}$ phosphors PL characteristics show the two emission peaks at around 378 and $425 \mathrm{~nm}\left(\lambda_{\text {exc }}=350 \mathrm{~nm}\right)$.

- Excitation wavelength of $\mathrm{Ce}^{3+}$ and $\mathrm{Dy}^{3+}$ activated alkali lanthanide tungstates in near UV region i.e. $\mathrm{Hg}$ free excitation, these characterization of phosphors is applicable for solid state lighting.

- Therefore, prepared $\mathrm{Ce}^{3+}$ and $\mathrm{Dy}^{3+}$ activated alkali lanthanide tungstates phosphors may be applicable for $\mathrm{Hg}$ free excited solid state low energy consumption lighting.

\section{Acknowledgement}

One of the authors (PN) is thankful to UGC for granting him a fellowship under its (FIP) programme.

\section{References}

Blasse G and Grabmaier B C 1994 Luminescent materials (Berlin, Heidelberg; Springer) p. 42

Dieke G H 1968 Spectra and energy levels of rare earth ions in crystals (New York: Interscience Publishers)

Dominiak-Dzik G, Ryba-Romanowski W, Kovács L and Beregi E 2004 Radiat. Meas. 38557

Feldmann C, Jüstel T, Ronda C R and Schmidt P J 2003 Adv. Funct. Mater. 13511

García-Cortés A et al 2007 IEEE J. Quantum Elect. 43157

$\mathrm{Gu}$ J et al 2010 Solid State Sci. (in press)

Güell F, Massons J, Gavaldà Jna., Pujol M C, Aguiló M and Díaz F 2007 Spain J. Appl. Phys. 101033108

Huang X, Lin Z, Hu Z, Zhang L, Huang J and Wang G $2004 J$. Cryst. Growth 269401 
Kaminskii A A, Bagaev S N, Grebe D, Eichler H J, Pavlyuk A A and Macdonald R 1996 Quantum Electron. 26193

Kaminskii A A et al 1999 Appl. Opt. 384533

Kasprowicz D, Mielcarek S, Trzaskowska A, Majchrowski A, Michalski E and Drozdowski M 2007 Cryst. Res. Technol. 421370

Kovács L, Borowiec M T, Majchrowski A, Baraldi A and Capelletti R 2005 Cryst. Res. Technol. 40444

Liang X, Zhu C, Yang Y, Yuan S and Chen G 2008 J. Lumin. 128 1162

Liu J et al 2005 Phys. Status Solidi (a) 4 R29

Mateos X, Pujol M C, Güell F, Solé R, Gavaldà Jna., Aguiló M, Díaz F and Massons J 2002 Phys. Rev. B66 214104
Mokhosoev M V, Alexeev F P and Lutsyk V I 1978 Phase diagrams of molybdate and tungstate systems (Nauka) p. 320 (in Russian) Neeraj S, Kijima N and Cheetham A K 2004 Chem. Phys. Lett. 3872

Shao Q, Li H, Wu K, Dong Y and Jiang J 2009 J. Lumin. 129879 Schubert E F and Kim J K 2005 Science $\mathbf{3 0 8} 1274$

Tang L and Wang G 2004 J. Cryst. Growth 274100033

Tzunov V K, Efremov V A and Velihkodnyi Yu A 1986 Crystallochemistry and properties of double molybdates and tungstates (Leningrad: Nauka) (in Russian)

Xiu Z L, Yang Z S, Lü M K, Liu S W, Zhang H P and Zhou G J 2006 Opt. Mater. 29431 